\title{
COMPARISON OF TECHNOLOGIES FOR METAL RADIOACTIVE WASTE DECONTAMINATION
}

\author{
Yavor LUKARSKI, Hristo ARGIROV, Ilian ATANASOV \\ Institute of Metal Science, Equipment and Technologies with a Centre for Hydro-and Aerodynamics "Acad. A. \\ Balevski”, Sofia, Bulgaria \\ e-mail:yasu@abv.bg
}

\begin{abstract}
A review is made of the growth dynamics of metal radioactive waste on a world scale. The most commonly applied technologies (hydro- and pyrometallurgical) for deactivation of this waste are presented.

The implementation of the blocks obtained by remelting for the manufacture of fasteners of nuclear reactors is demonstrated. Based on the conducted experiments and drawn conclusions, the inference is made that the pyrometallurgical methods of processing have greater advantages.

The paper exhibits a convincing motivation for the essential necessity of investigation of the metal radioactive waste processing, following the system $D \& D$ (deconstruction + deactivation), using effective and environmentally friendly technology.
\end{abstract}

KEYWORDS: nuclear reactor, radioactive waste, decontamination technologies, metallurgy under pressure

\section{Introduction}

Nuclear energy programs are being realized in more than 40 countries worldwide. According to summarized data of the International Atomic Energy Agency (IAEA) the number of the operating power units in 2016 was 443 and other 61 were under construction. There are also others at the "design" stage. The plants under operation with a nuclearthermal cycle (NTC) are 123, including 56 for uranium ore processing, 17 for uranium isotope separation, 50 for nuclear fuel production and spent nuclear fuel processing. About 30 NTC plants are either under construction or under design. The old installations with exhausted service life are 66 and they have to be decommissioned. In some countries there are reactors for weapon-grade plutonium production (14 such reactors in the USSR in 1987). In addition, 58 countries possess over 320 nuclear research facilities. Taking into account also 458 submarine atomic reactors, 29 reactors of military ships and 16 icebreaker reactors, the number of nuclear power facilities in operation exceeds 1400 . World nuclear power generation at the beginning of the XXI century has entered such a phase of its development, when the problems related to the exhausted service life and decommissioning of the nuclear energy facilities built in the 60s, 70s and some in the 80s of the XX century, have become especially topical [1].

It is obviously that the 21 st century is characterized by the exhausted resource of a great number of reactors: about 50 in the USA, 14 in Great Britain, over 20 in the Russian Federation. A number of reactors have to be decommissioned in Eastern Europe [2].

Large amounts of metal waste are generated during the process of nuclear installation decommissioning, which have to be treated in an appropriate manner by the D\&D (dismantling and decontamination) system. It is estimated that as of the present moment about $15 \cdot 10^{6} \mathrm{t}$ of radioactive waste of different origin are accumulated in the world [3].

The main problem to be solved during utilizing metal wastes from nuclear power plants is to reduce the level of their radioactivity for the purpose of further application. In case this is not possible, the waste should be compacted in order to use less space for its disposal. This is achieved mechanically or by melting the waste and pouring the liquid metal in moulds of suitable volume and shape. In this way the volume of the metal sent for disposal can be reduced up to 20 times [4].

Up to $95 \%$ of the radioactivity of metal waste obtained during dismantling NPP equipment is 
determined by the isotopes of $\mathrm{Cs}^{137}$ and cobalt ${ }^{60}$ [5]. In the process of metal melting the basic radionuclides with longer half-decay period (cesium, strontium, uranium, plutonium) are transferred in the slag and dust, captured in the filters, while in the metal remains mainly the isotope of cobalt ${ }^{60}$ (with a half-decay period of 5,3 years), which is distributed homogeneously in the ingot. This reduces significantly the storage time.

Depending on the residual contamination of the metal after crystallization, the blocks can be used in industry without restrictions or can be with limited utilization:

- Use for manufacturing facilities in nuclear industry as protective shields, radioactive waste (RAW) containers, parts for reactors and other equipment, etc.

- Storage in special repositories till the final decomposition of the radionuclides contained in them.

The metal blocks intended for unrestricted use in industry are ecologically safe for any kind of further processing. In addition, due to the deep purification of the metal and removal of the heavy nuclides such as cesium, strontium, uranium and plutonium, the necessary time for storage of the heavily contaminated blocks is sharply reduced till the decay of the remaining radionuclides in them (mainly $\mathrm{Co}^{60}$ ).

The present work considers the research and comparison of the different decontamination technologies and offers the most effective one for metal radioactive waste (MRAW).

\section{Technologies for MRAW decontamination}

There are different methods for MRAW decontamination - hydrometallurgical, chemical, electrochemical, mechanical, pyrometallurgical, etc.

The following criteria should be taken under consideration when selecting a specific technology:

- Safety: The implementation of the method should not lead to higher radiation;

- Effectiveness: The selected method should be able to remove radioactivity to the level that would allow manual treatment of the products for deactivation without the use of robots or recycling (reuse of materials) or at least their transfer to a lower category of contamination;

- Cost efficiency: Although in the case of deactivation of large amounts of radioactively contaminated metals the price is not of primary importance, the ratio between deactivation costs/revenues from scrap sales should also be taken into account;
- Minimization of wastes: The decontamination method must not result in producing large amounts of secondary radioactive waste.

\subsection{Hydrometallurgical technologies}

Hydrometallurgical technologies use the regularities of the chemical interactions between MRAW coatings and different types of solutions. In electrochemical processes the chemical interaction is accompanied by the action of an electric field.

The main advantages of chemical and electrochemical decontamination are:

- The processes are relatively elementary and are easy for control and operation;

- With the correct choice of chemicals almost all radionuclides can be removed from the surface of the treated element;

- Radioactivity can be removed from internal and hidden surfaces;

- Compared to the volume of liquids needed for chemical decontamination, the volumes of electrolytes for electrochemical deactivation are relatively low.

The chemical and electrochemical processes of decontamination have also certain disadvantages:

- Generation of relatively large amounts of liquid secondary waste (spent solutions), which have to be annihilated or deposited;

- Chemical decontamination is usually inefficient for treatment of porous surfaces;

- These methods are restricted in operation by the bath size and the geometry of treated surfaces.

A team with the participation of scientists and specialists from the Institute of Metal Science, Equipment and Technologies with a Center for Hydro- and Aerodynamics "Acad. A. Balevski" (IMSETCHA) of the Bulgarian Academy of Sciences has developed a project of an installation for surface decontamination of MRAW using hydrometallurgical methods;

The applied technology is a combination of physical, chemical and electrochemical decontamination methods. The deactivation is carried out in different modules - baths for alkaline, acidic and electrochemical decontamination. The spent solutions are neutralized, the radioactive sludge is compacted and the water is sent for treatment as lowlevel radioactive waste.

The main facilities used for implementing the technology are "Module for jet alkaline degreasing", "Module for jet chemical decontamination" and "Module for electrochemical decontamination".

It is envisaged that surface polluted MRAW will be subjected to decontamination in the installation, which according to the classification of Ordinance No 
7 of the Commission on the Use of Atomic Energy for Peaceful Purposes (CUAEPP) [6] fall into:

- I category (generated power of the equivalent dose at $0.1 \mathrm{~m}$ from the surface of $1 \cdot 10^{-3}$ to $3 \cdot 10^{-1}$ $\mathrm{mSv} / \mathrm{h})$;

- II category (generated power of the equivalent dose at $0.1 \mathrm{~m}$ from the surface of $3 \cdot 10^{-1}$ to $10 \mathrm{mSv} / \mathrm{h}$ ).

- At the stage of trial operation of the installation no treatment of metal RAW of the II category is envisaged, which generates power of the equivalent dose at $0.1 \mathrm{~m}$ from the surface exceeding 2 $\mathrm{mSv} / \mathrm{h}$.

The expected surface $\beta+\gamma$ contamination is from $2 \mathrm{~Bq} / \mathrm{cm}^{2}$ to $50 \mathrm{~Bq} / \mathrm{cm}^{2}$, the expected equivalent dose rate of gamma radiation $\mathrm{P} \gamma$ is from $0.1 \mathrm{mSv} / \mathrm{h}$ to about $5 \mu \mathrm{Sv} / \mathrm{h}$.

\subsection{Pyrometallurgical technology}

Most of the technologies developed by leading companies for the utilization of radioactively contaminated metals include several basic stages: sorting of metals according to the level of radioactive contamination; cutting; preliminary deactivation to remove fission and activation products, contained in coatings, depositions, oxide layers and dust in the facility; remelting of the metal waste.

The principles of metallurgical thermodynamics are in the basis of the processes of transferring heavy nuclides to the slag. The effect of enthalpy and entropy on the direction and degree of a chemical reaction is given by the equation of Gibbs [7]:

$$
\Delta \mathrm{G}=\Delta \mathrm{H}-\mathrm{T} \cdot \Delta \mathrm{S}
$$

Here $\mathrm{T}$ is the absolute temperature, $\mathrm{K}$.

The stability of the single oxides can be seen in the diagram of Ellingham [8]. It shows the dependence of the free energy $\Delta \mathrm{G}$ on temperature for the individual oxides. The more negative the $\Delta \mathrm{G}$ value, the more stable the oxide.

In general, the metals with lines below the line of iron can be oxidized and transferred from the molten steel into slag. The metals with lines above the line of iron cannot be oxidized. Cobalt will remain in the melt because the line of cobalt oxide is above that of iron. Uranium will pass into the slag because the position of the line of uranium oxide is below that of iron oxide.

After analysing the processes of MRAW melting, the decision was made to propose two melting technologies, one of them being with two options for realization [9].

\subsubsection{Processing of metal RAW using fluxes}

The scrap, cut and cleaned of organic and other contaminants, is fed into an induction furnace - Fig. 1 [9].

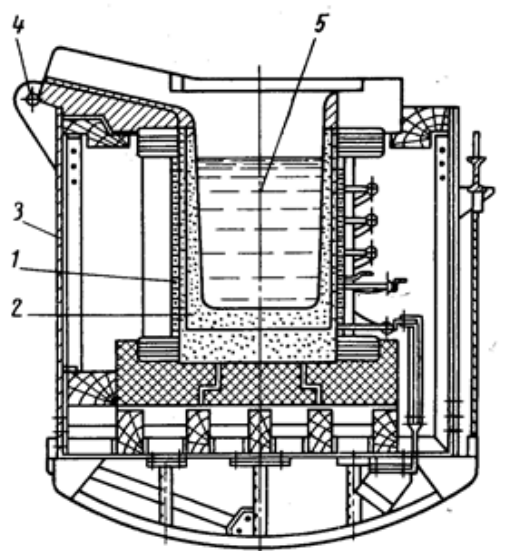

Fig. 1. Crucible induction furnace:

1 - inductor; 2 -crucible; 3 - supporting structure; 4 - furnace inclination mechanism; 5 - molten metal [9]

After reaching the specified temperature, special refining fluxes are introduced into the liquid metal in the amount of $2-3 \%$ of its mass but up to $10 \%$ of the melt mass can be reached. Flux composition depends on the radioactive element content in the scrap and on slag alkalinity. Usually the fluxes contain quartz sand, lime, dolomite, magnesium and additives regulating slag viscosity (for example $\mathrm{CaF}_{2}$ ). The liquid metal is stirred due to the magnetic field generated by the inductor and the temperature gradient along the height of the induction furnace crucible. After a delay of 15-20 min allowing the completion of the refining processes, the furnace power is reduced, and the slag is scraped off. The metal is cast in molds.

This technological solution may also have another option of performance, which is more expensive, but more efficient, namely MRAW processing with additional metal treatment in a foundry ladle. In this case scrap is fed into the furnace, melted and overheated by about $50-100{ }^{\circ} \mathrm{C}$ above the specified temperature in order to prevent overcooling of the melt when poured in the ladle. In addition, it is necessary that the ladle should be heated too. The metal melted in the induction furnace is poured into the ladle, which has a porous plug at the bottom. An inert gas (nitrogen, argon) is blown through it. The refining fluxes are fed in the specified quantity and the metal is intensively stirred. After 1015 min the gas flow is stopped, the slag is scraped off and the metal is poured in moulds. 


\subsubsection{Processing of MRAW without using fluxes}

No refining fluxes are introduced in this technological solution. On the other hand, after overheating of the metal it is maintained at the given temperature twice as long, so that the light isotopes are transferred to the gas phase and then to the gascleaning facilities. With this process it is practically impossible to obtain metal ready for unrestricted use and therefore it is recommendable to apply it for melting of relatively pure scrap with respect to radioactive contamination.

\subsubsection{Comparison of the three technological processes}

In terms of technological complexity, the most easily implemented process is that of MRAW treatment without using fluxes. Its main shortcoming was mentioned above. The most complicated technological method is the processing of MRAW with an additional treatment of the metal in a foundry ladle. The problem with this technological process is to maintain a specified temperature of the liquid metal in the ladle during the refining processes. The temperature has to be constantly monitored in order to avoid a situation when the metal cools down and the refining processes stop. The most frequently used method is to heat the ladle through its lid.

In terms of overall productivity, the technological processes for MRAW treatment, with or without using fluxes, are comparable because the time for refining the melt with fluxes is comparable to the additional heating in the flux-free option. In the case of MRAW treatment with additional processing of the metal in a foundry ladle, the productivity is lower due to the more complicated technology and the additional time for pouring the metal into the ladle and its refining under conditions of gas blowing. This process is most effective in terms of the production of metal intended for unrestricted use, also reducing the relative share of the other two groups of treated metal - for restricted use and for disposal.

The technological process for MRAW treatment without using fluxes can be most easily implemented because no additional devices for flux feeding and slag scraping are necessary. The method of MRAW processing with additional treatment of the metal in a foundry ladle is most complicated.

After analysing the results from the comparison of the single technological solutions, the authors consider that the most advantageous option is to melt MRAW in an induction furnace with introduction of a certain amount of refining fluxes without additional heating.

\section{Application of the decontaminated scrap}

A method is shown of implementing the already decontaminated by melting metal scrap, unconditionally released from control based on low residual radioactivity [10]. This metal can be implemented as a raw material in the production of fasteners for nuclear reactors. In this case these are studs for the outer contour with sizes: length of 2000 $\mathrm{mm}$, diameter of $120 \mathrm{~mm}$ and mass of $180 \mathrm{~kg}$ each.

The steel 32NiCrMo of type (DIN 1.6745), used as a basis, is of the type of the constructional complexly alloyed medium-carbon steels, intended for the manufacture of fasteners for nuclear reactors. A new steel brand of the type 30Cr2NiMoVN with higher nitrogen content has been developed by mathematical modeling using artificial neural networks of the dependence "steel properties/chemical composition". It is produced using the methods of the metallurgy under pressure. The method is applied to produce new steels and alloys under higher pressure compared to the atmospheric one. The theoretical grounds of the alloying with super-equilibrium nitrogen concentrations were developed in IMSETCHA-BAS. The main advantages of this type of metallurgy are: replacement of expensive alloying elements (nickel) by nitrogen, which is distributed homogeneously in the bulk of the metal; smooth and homogeneous filling of the crucible with metal; improved structure and high density of castings.

The conducted investigations on both steels prove that the new one has a fine-grained structure of the strengthening phase, which ensures $30-50 \%$ higher strength and plastic properties as well as impact toughness. Therefore, it can be operated without problems up to $\mathrm{T}=350{ }^{\circ} \mathrm{C}$, for fasteners of nuclear reactors in particular.

The next step in stud production is to obtain the intermediate blanks in a ВП-0,5 induction furnace, where the scrap is calculated so as to use the contaminated and remelted blocks yielded by metal utilization from decommissioned plants. Even if minimal residual radiation is present in them, when dissolved in the liquid bath, the residual nuclide values are negligibly small. Further on the metal rods of the new steel are subjected to Electroslag Remelting under nitrogen pressure and blanks of the $30 \mathrm{Cr} 2 \mathrm{NiMoVN}$ steel are obtained. Then the studs are forged and finally mechanically treated. The finished studs are shown in Fig. 2 [10]. The PWR reactor in operating position with the mounted stubs is seen in Fig. 3 [10]. 


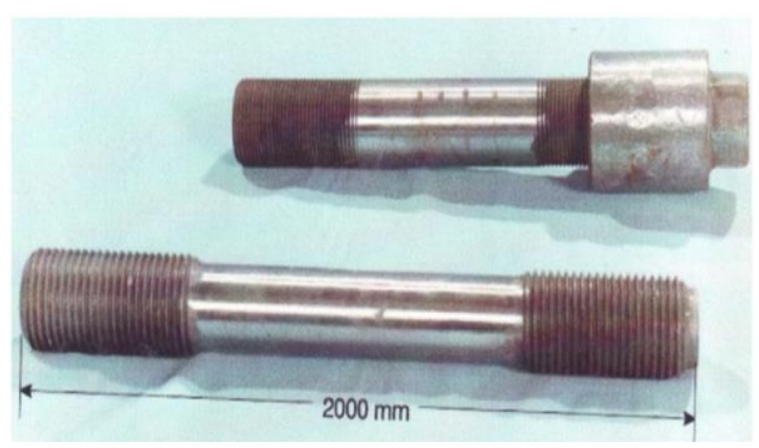

Fig. 2. Fasteners of steel 30Cr2NiMoVN. Length $2000 \mathrm{~mm}$, diameter $120 \mathrm{~mm}$ [10]

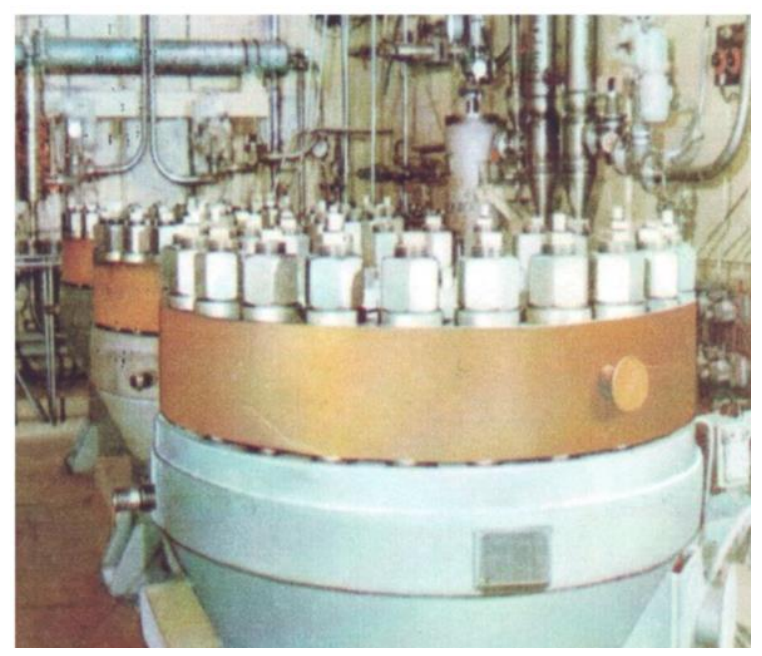

Fig. 3. Outer contour of $P W R$ reactor with mounted studs [10]

\section{Comparison of the two types of MRAW decontamination technologies}

When analysing the specifics of both technologies, several things have to be pointed out:

First, hydrometallurgical methods are more complex and require higher efforts from the service personnel in contrast to the pyrometallurgical ones, which are simpler in terms of operation and maintenance. The fact that in the case of the "wet" methods the staff works under conditions of evaporating chemical substances should not be ignored too. Additional, significant amounts of secondary RAW are generated, which require special attention, it becomes clear that the hydrometallurgical methods are lagging behind the development of the pyrometallurgical ones.

The main advantage of the latter is the possibility of multifold reduction of the volume of melted materials with all ensuing beneficial consequences. This is not relevant to the hydrometallurgical processes, where the shape and volume of scrap are not changed during treatment. The more salubrious work environment in the pyrometallurgical technologies, as well as the possibilities for automation of a great part of the processes have to be also taken into account [11].

The decontamination of MRAW by melting and processing with refining fluxes has also the advantage that redistribution of radioactive nuclides occurs between the metal block, slag and dust in the purification filters, thus achieving additional deactivation of the primary material. Moreover, uniform distribution of residual radioactivity is obtained in the volume of the ingot.

\section{Conclusion}

Based on the conducted research and pilot trials the team determines that the most prospective method for MRAW processing is by melting the metals in an induction furnace. Refining fluxes are introduced during melting, which reduce the number of radioactive nuclides, and the produced metal is subjected to unconditional release from control. The ideal option would be to cut and preliminary treat the dismantled elements applying some of the hydrometallurgical or mechanical methods and then to melt them in an induction furnace. However, this will make the decontamination technology rather expensive.

\section{References}

[1]. ***, Communication of the Ural Electrochemical Plant, Out. No 16-30/659 from 13.05.99, (in Russian).

[2]. Slaveykova M. E., Demireva G. Simova. Estimate of the streams of dismantled materials from EE of Units 1 and 2 of "Kozloduy" Nuclear Power Plant, Conf. of the Bulgarian Nuclear Society, 10-13 Oct., 2012, Hisarya, Bulgaria, (in Bulgarian).

[3]. Quade U., Kluth T., Kreh R., Melting of Low-Level Radioactive Non-Ferrous Metal for Release, Proc. ICEM '07, Paper 7036, Brügge, Sept., 2007.

[4]. Quade U., Kluth T., German Experience in Recycling of Ferrous Metallic Residues from Nuclear Decommissioning by Melting, Proc. SFEN, Decommissioning Challenges: An Industrial Reality, Avignon, Sept., 2008.

[5]. Andreev D. E., Gelbutovski A. B., Existing Practices and Economic Aspects of the Problem of the Treatment of Metal Radioactive Waste, ZAO „ECOMET-C“, Report from 07.10.2005, (in Russian).

[6]. ***, Regulation No 7 of the Committee on the use of nuclear energy for peaceful purposes for collection, storage, processing, transport and disposal of radioactive waste on the territory of the Republic of Bulgaria, State Gazette, No 8/1992, https://www.bcci.bg/bulgarian/eurozone/negotiations. (in Bulgarian).

[7]. Cotton F., Wilkinson G., Basic Inorganic Chemistry, New York. John Wiley \& Sons, 1979.

[8]. Cotton F. A., Wilkinson G., Gaus P., Basic Inorganic Chemistry, $7^{\text {th }}$ edition, J. of Chemical Education, № 77(3), March, 2000.

[9]. Lukarski Y., Argirov Cr., Possibilities of Optimizing the Processing of Metallic Radioaktive Waste, NDT Journal, vol. II, Issue 2, p. 125-133, 2019. 


\section{THE ANNALS OF "DUNAREA DE JOS" UNIVERSITY OF GALATI \\ FASCICLE IX. METALLURGY AND MATERIALS SCIENCE \\ $\mathrm{N}^{\circ} .2$ - 2021, ISSN 2668-4748; e-ISSN 2668-4756 \\ Article DOI: https://doi.org/10.35219/mms.2021.2.05}

[10]. Kortenski G., Argirov H., Effect of Hydrogen on the Mechanical Properties and Notch Toughness of Hewly Created Steel, J. of Theoretical and Appl. Mechanics, №1, p. 83-86, 1996.

[11]. Lukarski Y., Atanasov I., Argirov Ch., Protection of the Personnel from Irradiation during Pyrometallurgical Processing of the Base of Model Calculations, $27^{\text {th }}$ International Conf. Ecological Truth and Environmental Research "EcoTER", Bor, Serbia, June, p. 404-411, 2019 